\title{
The Psychological and Socio-political Consequences of Infectious Diseases
}

\author{
Leor Zmigrod $^{1,2}$, Tobias Ebert ${ }^{3}$, Friedrich M. Götz ${ }^{1}, \&$ Peter Jason Rentfrow ${ }^{1}$ \\ Affiliations: $\quad{ }^{1}$ Department of Psychology, University of Cambridge, Cambridge, UK \\ ${ }^{2}$ Behavioural and Clinical Neuroscience Institute, University of Cambridge, \\ Cambridge, UK \\ ${ }^{3}$ Mannheim Centre for European Social Research, University of Mannheim, \\ Mannheim, Germany
}

\section{April 2020: THIS IS A PREPRINT - THE MANUSCRIPT IS CURRENTLY UN- DER PEER REVIEW.}

\begin{abstract}
What are the socio-political consequences of infectious diseases? Humans have evolved to avoid disease and infection, resulting in a set of psychological mechanisms that promote disease-avoidance, referred to as the behavioural immune system (BIS). One manifestation of the BIS is the cautious avoidance of unfamiliar, foreign, or potentially contaminating stimuli. Specifically, when disease infection risk is salient or prevalent, authoritarian attitudes can emerge that seek to avoid and reject foreign outgroups while favoring homogenous, familiar ingroups. In the largest study conducted on the topic to date $(N>240,000)$, elevated regional levels of infectious pathogens were related to more authoritarian attitudes on three geographical levels: across US metropolitan regions, US states, and cross-culturally across 47 countries. The link between pathogen prevalence and authoritarian psychological dispositions predicted conservative voting behavior in the 2016 US Presidential Election as well as more authoritarian governance and state laws, in which one group of people imposes asymmetrical laws on others in a hierarchical structure. Furthermore, cross-cultural analysis illustrated that the relationship between infectious diseases and authoritarianism was pronounced for infectious diseases that can be acquired from other humans (nonzoonotic), and does not generalize to other infectious diseases that can only be acquired from non-human species (zoonotic diseases). At a time of heightened awareness of infectious diseases, these findings are important reminders that public health and ecology can have ramifications for socio-political attitudes, and this can shape how citizens vote as well as how they govern and are governed.
\end{abstract}




\section{Introduction}

The behavioural immune system (BIS) is a highly adaptive motivational system that diminishes risk of infection by altering information processing and behavior to prevent pathogen transmission (Ackerman, Hill, \& Murray, 2018). The system detects potentiallythreatening environmental stimuli and promotes cognitive and affective reactions that reduce contact with these stimuli. For instance, upon sight of a potentially contaminating substance, humans typically experience the emotion of disgust, which fosters aversion and avoidance. Similarly, ecological conditions characterized by high levels of infectious diseases can promote behavioural adaptations associated with conforming to established traditions and avoiding foreign and potentially-infectious stimuli (Falkner, Schaller, Park, \& Duncan, 2004; Fincher \& Thornhill, 2012; Navarette \& Fessler, 2006). By encouraging the individual to minimize contact with unfamiliar targets and to seek targets that are known and recognizable, the BIS provides a "first line of defense against contamination" (Terrizzi, Shook, \& McDaniel, 2013).

Research in social psychology has illustrated that disease-avoiding motivations can have profound implications for social behavior and cultural outcomes: activating the BIS with threat-relevant cues leads individuals to avoid unfamiliar social targets and to conform to familiar social targets. Specifically, two lines of empirical evidence have converged in support of the hypothesis that human motivations to avoid pathogens shape socio-political attitudes by facilitating hostility towards outgroups and augmenting preferences for social conformity. Firstly, at the level of individual psychology, when the perception of infection risk is elevated, individuals tend to adopt more conformist and conservative attitudes (Helzer \& Pizarro, 2011; Inbar, Pizarro, Bloom, 2009; Jones \& Fitness, 2008; Murray \& Schaller, 2012; Wu \& Chang, 2012). Furthermore, individuals who experience greater levels of disgust in response to pathogen cues are more likely to endorse more xenophobic, ethnocentric, morally-vigilant attitudes (e.g. Navarette \& Fessler, 2005; Faulkner et al., 2004; Murray, Kerry, \& Gervais, 
2019; Luizza et al., 2018, 2019; Schnall, 2016; Stewart, Adams, \& Senior, 2020; Zakrzewska et al., 2019; but see: van Leeuwen \& Petersen, 2018). Consequently, an individual's sensitivity to contamination-related and disgust-provoking cues may fundamentally shape their sociopolitical attitudes.

The second line of evidence comes from cross-population studies which have found associations between geographical variations in pathogen prevalence and the emergence of more ethnocentric, collectivist, and conservative cultural attitudes. Higher levels of parasite stress are related to greater regional political authoritarianism and social conservatism (Murray, Schaller, \& Suedfeld, 2013; Terrizzi, Shook, McDaniel, 2013; Thornhill, Fincher, \& Aran, 2009; but see: Horita \& Takezawa, 2018), prioritization of obedience and intolerance of nonconformity (Murray, Trudeau, \& Schaller, 2011; Tybur et al., 2016), heightened collectivism and endorsement of binding moral concerns (Fincher, Thornhill, Murray, Schaller, 2008; Van Leeuwen, Park, Koenig, \& Graham, 2012), moral vitalism (Bastian et al., 2019), and increased frequency of intrastate armed conflict (Letendre, Fincher, \& Thornhill, 2010). Higher ecological prevalence of infectious diseases therefore appears to promote societal norms that are more conservative and authoritarian.

The current study therefore combined the methodologies of individual-focused psychology and cross-population studies in order to test whether regional pathogen prevalence promotes authoritarian psychological dispositions, which in turn shape real-world political outcomes. Specifically, it sought to address three primary questions: (Q1) Are higher rates of infectious diseases related to more authoritarian attitudes? (Q2) Does the relationship between infectious diseases and authoritarian attitudes explain real-world outcomes such as voting behavior and law? And (Q3) is this effect specific to infections that can be acquired from humans (nonzoonotic diseases, i.e. "socially-relevant infections") as opposed to infections that can be acquired only from non-human species (zoonotic diseases, "asocial infections")? 
Addressing these questions would elucidate the psychological mechanisms underlying the effect of infectious diseases on socio-political outcomes.

\section{Are higher rates of infectious diseases related to more authoritarian attitudes?}

The study examined whether rates of infectious diseases are related to more authoritarian psychological dispositions across multiple geographical spatial levels: between US metropolitan regions, between US states, and between nations. Our data consisted of 241,249 participants, and was obtained through a survey popularized on the TIME Magazine website (see Methods). This sample included 194,131 participants residing in the USA, and the rest $(\mathrm{N}=47,118)$ were residents of 46 other nations (see Methods). Participants were invited to complete an authoritarianism personality survey, in which they were presented with four pairs of traits, and were asked to indicate the quality that they believed is more important for a child to possess: "independent or respectful"; "obedient or self-reliant", "well-behaved or considerate", and "well-mannered or curious". This measure has been widely used in social and political psychology (e.g., Brandt \& Reyna, 2014; Brandt \& Henry, 2012; Crawford, Brandt, Inbar, \& Mallinas, 2016; Federico, Fisher, \& Deason, 2011; Feldman \& Stenner, 1997; Hetherington \& Suhay, 2011; Hetherington \& Weiler, 2009; Stenner, 2005; Zmigrod, Rentfrow, \& Robbins, 2018) and does not conflate authoritarianism with political ideology or fundamentalism, unlike other authoritarianism measures (Hetherington \& Weiler, 2009; Mavor et al., 2009, 2011; Stenner, 2005). Participants were also invited to provide their zip code of residence.

To quantify regional pathogen prevalence across the three levels of geographical analysis, we followed literature standards in calculating regional infectious diseases or historical pathogen prevalence rates (see Methods), using multiple pathogen prevalence indices 
to replicate effects wherever data were available. All of the US-based analyses controlled for five key socio-economic variables relevant to political attitudes and voting behavior, in line with geographical psychology conventions (Garretsen et al., 2018; Obschonka et al., 2018; Rentfrow, 2010; Rentfrow et al., 2013): (1) religiosity, (2) economic climate, (3) ethnic composition, (4) educational attainment (human capital), and (5) industrial composition. The cross-cultural analyses controlled for an analogous set of socio-economic variables, informed by covariates identified by past cross-cultural analyses of pathogen prevalence (Murray, Schaller, \& Suedfeld, 2013): (1) religiosity, (2) economic climate, (3) wealth inequality, (4) educational attainment (human capital), and (5) life expectancy. All analyses controlled for these socio-economic variables unless otherwise stated.

As evident in Figure 1, infectious disease prevalence was positively related to authoritarian attitudes across US metropolitan regions $(\beta=.345, p=.003)$, US states $(\beta=.596$, $p=.033$; Figure 2$)$, and cross-culturally $(\beta=.790, p=.001)$, after controlling for all relevant socioeconomic variables and sample characteristics.
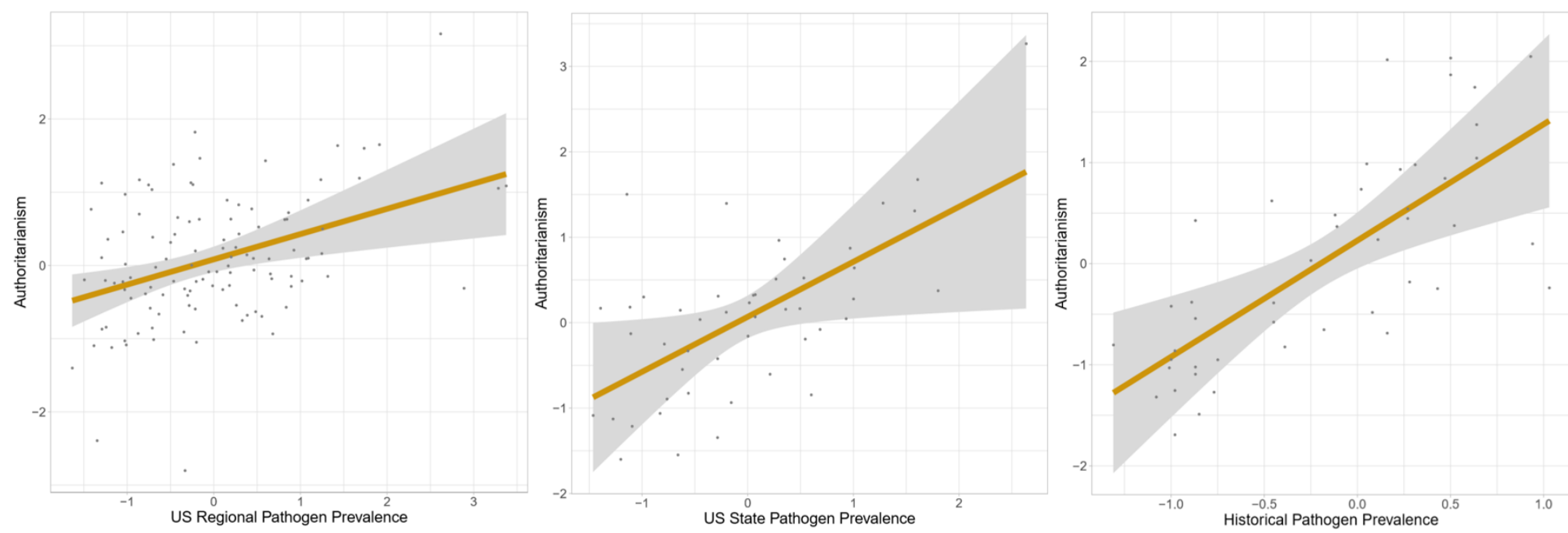

Figure 1. The relationship between authoritarian attitudes and pathogen prevalence across (A) US metropolitan regions, (B) US states, and (C) nations, controlling for sample characteristics (age and gender) and regional socio-economic characteristics. Shaded area reflects $95 \%$ confidence intervals. 
Pathogen Prevalence

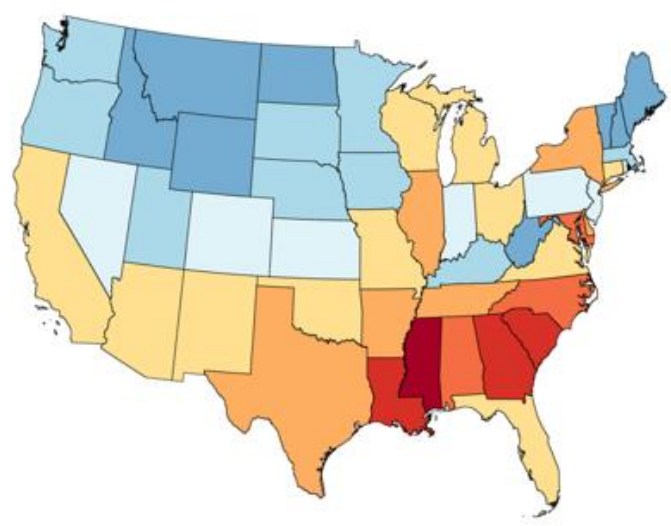

Authoritarian Attitudes

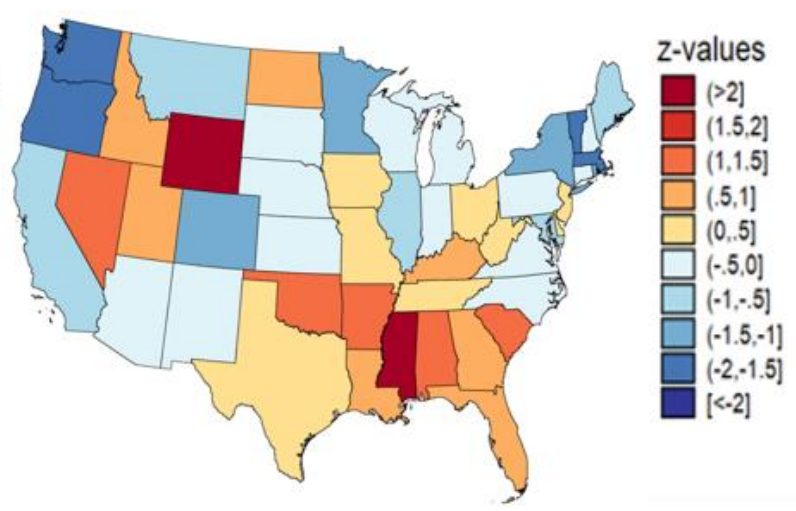

Figure 2. Pathogen prevalence and distribution of authoritarian attitudes across US states.

\section{Does the relationship between infectious diseases and authoritarian attitudes explain real-world outcomes such as voting behavior and law?}

Building on past findings and theory, we examined whether infectious diseases rates predict regional conservative voting behavior in the 2016 US Presidential Election across US metropolitan regions and states, and whether these relationships were mediated by heightened authoritarian attitudes. Pathogen prevalence was a significant positive predictor of the percentage of citizens in a region who voted for the Republican Presidential candidate in the 2016 US Election in US metropolitan regions ( $\beta=.253, p=.023)$ and states $(\beta=.587, p=.004)$, controlling for sample characteristics and regional socio-economic characteristics. Mediation analyses were consequently conducted using a bias-corrected bootstrapping procedure (MacKinnon \& Fairchild, 2009; Preacher \& Selig, 2012), with 10,000 bootstrapped iterations. To validate this further, we also employed the Monte Carlo method for testing mediation (in line with the methodological recommendations of Hayes and Scharkow (2013)). This was achieved by constructing 95\% confidence intervals around the unstandardized indirect effects (MacKinnon et al., 2004; Preacher \& Selig, 2012), using 50,000 simulations. Confidence intervals that exclude zero are considered significant. As indicated by Figure 3, across both US 
metropolitan regions and US states, authoritarian attitudes mediated the relationship between pathogen prevalence and regional conservative political outcomes in the 2016 Election using both the bias-corrected bootstrapping procedure and the Monte Carlo procedure. The mediation effect sizes were large across both geographical levels. After accounting for authoritarianism, the direct effect between pathogen prevalence and conservative voting outcomes was no longer significant, suggesting a full mediation across both geographical levels. Consequently, heightened rates of infectious diseases were related to elevated authoritarian attitudes, which in turn were associated with more conservative political outcomes in the US.

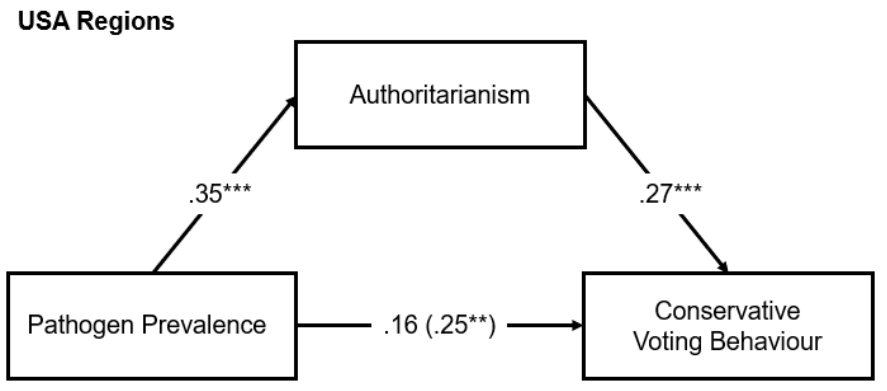

Bootstrapped indirect effect: $\beta=.10[.01, .09]$, mediation effect size: $40 \%$ Monte Carlo $95 \%$ Cl: $[.021, .196]$

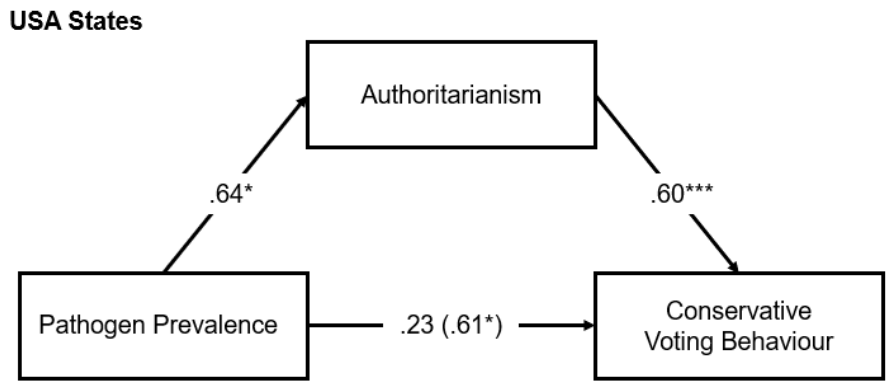

Bootstrapped indirect effect: $\beta=.41[.04, .94]$, mediation effect size: $67 \%$ Monte Carlo $95 \% \mathrm{Cl}$ : [.041, .791]

Figure 3. Authoritarian attitudes mediate the relationship between regional pathogen prevalence and regional conservative voting behavior in the 2016 US Presidential Election across (A) US metropolitan regions and (B) US states, controlling for sample characteristics (age and gender) and regional socio-economic characteristics. Values represent standardized beta coefficients. The value in parentheses indicates the total effect. Confidence intervals that exclude zero are significant. $* p<.05, * * p<.01$, ***p<.001.

Infectious diseases and authoritarianism are thus linked to who citizens elect for political governance, and so we examined whether this pattern is also manifest with regards to how citizens are governed. To measure authoritarian governance, we used the vertical legal restrictions index, created and validated by Conway and colleagues (2017), which reflects the presence of laws in which one group of people imposes asymmetrical laws on others in a hierarchical structure. Specifically, the index reflects the presence of restrictive laws (or the 
absence of laws protecting freedom) in three general areas of legal restriction that have been theoretically linked to the facilitation of hierarchies in which some minority groups' freedoms are unequally restricted: abortion, extreme criminal punishment, and LGBT rights (see Conway et al. 2017 for details). These vertical legal restrictions contrast with "horizontal" restrictions, in which the laws restrict most members of a society in an equal fashion (Conway et al., 2006, 2014). Consequently, the difference between vertical and horizontal legal restrictions reflects the difference between "laws that only apply to minority groups" and "laws that apply to all persons equally", respectively. Vertical legal restrictions are therefore a proxy measure of authoritarian governance, in line with Murray and colleagues' (2013) definition of authoritarian governance as "highly concentrated power structures that repress dissent and emphasize submission to authority, social conformity, and hostility towards outgroups" (Murray et al., 2013, p. 1).

Vertical legal restrictions in a state were significantly positively related to its pathogen prevalence $(r=.356, p=.013)$, while horizontal legal restrictions were not $(r=.262, p=.072)$. Vertical and horizontal legal restrictions were not correlated ( $r=-.156, p=.289)$, consistent with Conway and colleagues' (2017) findings. This suggests that the vertical and horizontal legal restriction indices tap into separable constructs. Furthermore, there was a significant mediation effect of the relationship between US state pathogen prevalence and authoritarian state laws via authoritarian attitudes: heightened pathogen prevalence predicted elevated levels of authoritarianism, which in turn predicted more authoritarian state governance (Figure 4). This suggests that vertical legal restrictions, and not merely the general presence of legal restrictions, are related to pathogen prevalence and authoritarian psychological dispositions.

To further investigate whether the relationship between pathogen prevalence and authoritarianism explained real-world outcomes, we examined authoritarian governance between nations. Following the methodology of Murray and colleagues (2013) we found that 
undemocratic governance systems - as operationalized with the Vanhanen's index of democracy - are related to infectious diseases and authoritarian attitudes in a similar fashion to the patterns observed on the US metropolitan and state levels. The mediation persisted when accounting for the sample age and gender characteristics, but in line with the findings of Murray and colleagues (2013) and Tybur and colleagues (2016) did not persist after accounting for broader national socioeconomic variables such as educational attainment, wealth, and religiosity, suggesting that these variables may play a role in these relationships. Cross-cultural analyses with a larger range of countries will be more well-powered to address these nuances.

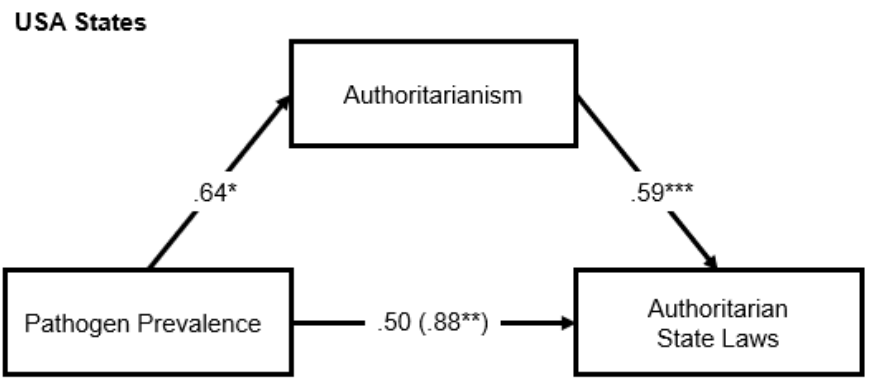

Bootstrapped indirect effect: $\beta=.38[.04, .86]$, mediation effect size: $43 \%$ Monte Carlo $95 \% \mathrm{Cl}$ : $[.032, .842]$

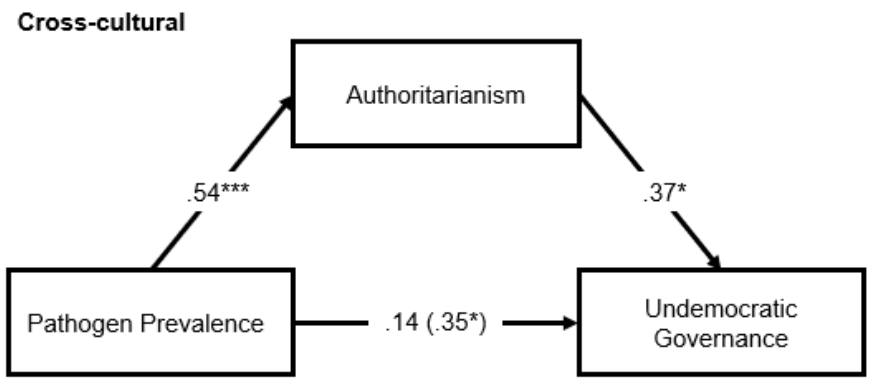

Bootstrapped indirect effect: $\beta=.21[.04, .41]$, mediation effect size: $60 \%$ Monte Carlo $95 \% \mathrm{Cl}$ : [.027, .488]

Figure 4. (A) Authoritarian attitudes mediate the relationship between regional pathogen prevalence and authoritarian (vertical) US state laws, controlling for sample demographic characteristics (age and gender) and regional socio-economic characteristics. (B) Authoritarian attitudes mediate the relationship between historical pathogen prevalence and undemocratic governance, controlling for sample demographic characteristics (age and gender). Values represent standardized beta coefficients. The value in parentheses indicates the total effect. Confidence intervals that exclude zero are considered significant. * ${ }_{p}<.05$, $* * p<.01, * * * p<.001$.

\section{Is this relationship pronounced in nonzoonotic (human-to-human) infectious}

\section{diseases rather than zoonotic (asocial) diseases?}

The parasite-stress theory of authoritarianism posits that the costs of being infected by out-group human members would motivate more authoritarian behavior. It therefore predicts that infectious diseases that can be transmitted between humans would be more relevant to authoritarianism than infectious diseases that cannot be transmitted between humans (Thornhill 
et al., 2010; Fincher \& Thornhill, 2012). Epidemiologists have identified that there are two types of infectious diseases that humans can acquire: (1) nonzoonotic diseases, which can be acquired from other humans or animals and transmitted onto other humans (e.g. measles, cholera, leprosy), and (2) zoonotic diseases, which can only be acquired from non-human species (e.g. lyme disease, rabies). Consequently, we tested whether nonzoonotic infectious diseases were indeed related more strongly to authoritarian attitudes than zoonotic diseases. Data on nonzoonotic and zoonotic infections is only publicly available on the cross-national level and so we analyzed it in the 47 country dataset.

Regression analyses corroborated this hypothesis: nonzoonotic infectious diseases were more important for explaining authoritarian attitudes than zoonotic diseases. A multiple linear regression analysis predicting national authoritarian attitudes was conducted $(F(7,38)=4.634$, $p<.001, \mathrm{R}^{2}=46.05 \%$ ), including the socio-economic covariates outlined above (all were insignificant predictors at $p>.05$ ) and the rates of nonzoonotic and zoonotic parasite prevalence. Nonzoonotic parasite prevalence was a significant positive predictor of authoritarian attitudes $(\beta=.669, t=2.656, p=.012)$, while zoonotic parasite prevalence was not a significant predictor $(\beta=-.105, t=-.544, p=.590)$. This was supported by a Bayesian analysis. Computing the Bayesian regressions and associated Bayes factors for all possible combinations of socioeconomic predictors and the nonzoonotic and zoonotic parasite prevalence predictors allows us to balance predictive power and parsimony through the removal of redundant predictors. This analysis revealed that the best model out of all possible predictor combinations is the one that predicts authoritarianism only with the nonzoonotic parasite prevalence measure, and no other socio-economic measure or the zoonotic parasite prevalence. The Bayes factor for this model was $\mathrm{BF}_{10}=17,236$, indicating that the data are 17,236 times more likely under this model than an intercept-only null model $\left(\mathrm{H}_{0}\right)$. Figure 5 depicts the Bayes factors for regression models predicting authoritarianism with a single predictor each time. Moreover, the nonzoonotic- 
parasite-only model (subscript $\mathrm{N}$ ) was over 13 times more likely than a model predicted by all the five socio-economic factors (subscript $\mathrm{S} ; \mathrm{BF}_{\mathrm{NS}}=13.733$ ).
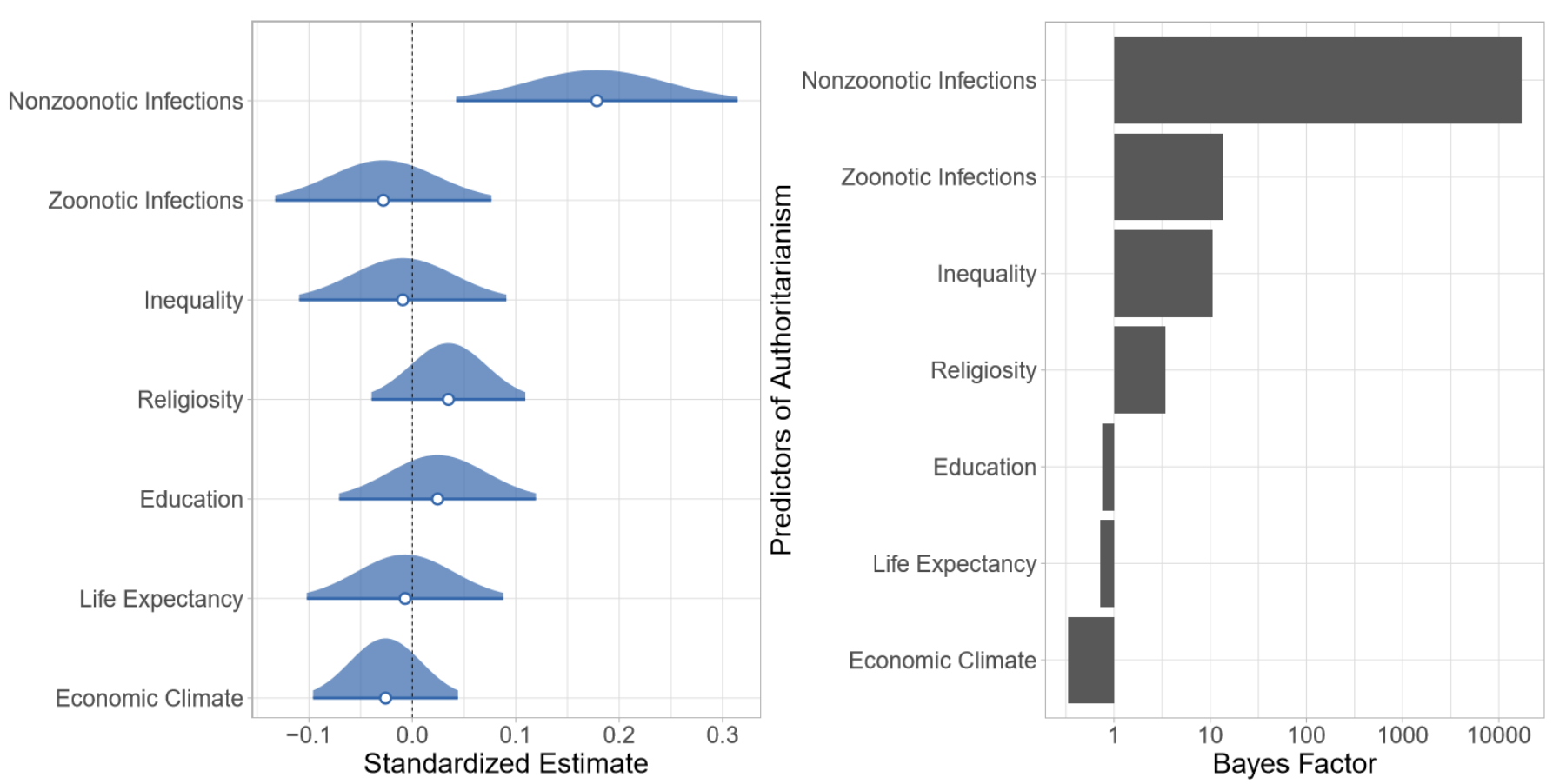

Figure 5. Regression results predicting national authoritarian attitudes from nonzoonotic infectious diseases (acquired from humans), zoonotic infectious diseases (acquired from nonhumans), and socio-economic characteristics, controlling for sample characteristics (age and gender). (A) Standardized beta estimates with $95 \%$ confidence intervals. (B) Bayes Factors for each predictor. In accordance with Jeffreys (1961), Bayes Factor (BF) above 10 indicates strong evidential strength, BF>30 indicates very strong evidence, and BF>100 indicates decisive evidence in favor of the predictor.

\section{Discussion}

The findings reveal a robust relationship between regional infectious disease rates and psycho-political preferences for conformity and hierarchical power structures. This relationship is evident across three geographical spatial levels and predicts real-world outcomes such as conservative voting behavior and authoritarian governance. Moreover, a fine-grained analysis of infection type specifically implicates nonzoonotic infections that can be acquired from other humans - the findings do not generalize to zoonotic infections that can only be acquired from non-human species. Psychological and political behavior is thus shaped 
specifically by socially-relevant infections, in which the behavioural immune system (BIS) can motivate individuals to avoid dissimilar others and hence prefer authoritarian power relations. Public and personal health can therefore have fundamental repercussions for regional politics, decision-making, and governance.

The results indicate that population-level epidemiological profiles of infectious diseases may structure individual-level psychological preferences as well as the allocation of social and political power. Future research will need to adopt longitudinal designs that can rigorously test causality and evaluate how private experiences of infection and infection risk can shape psychological and political outcomes. As COVID-19 becomes a global pandemic, it is imperative to consider the consequences of infectious diseases for citizens' psychology and politics. It may also be essential to identify antidotes to these effects. Indeed, emerging evidence suggests that chronic activation of the BIS can shape social cognition (Kavaliers \& Choleris, 2018), legal juror decision-making and the evaluation of evidence (Brown, Rodriguez, Gretak, \& Berry, 2017; Sevi \& Eskenazi, 2018). Disease outbreaks can also increase voters' preferences for politically conservative candidates (Beall, Hofer, \& Schaller, 2016; Kim, Sherman, \& Updegraff, 2016). Notably, the cross-cultural analyses presented here show that historical pathogen prevalence still predicts contemporary ideological attitudes, and so if COVID-19 elevates the allure of authoritarian ideologies, the effects could be long-lasting. Authoritarian attitudes have bidirectional links with cognition and perception (e.g. Zmigrod et al., 2018, 2019a, 2019b; Zmigrod, 2020), sociality (e.g. Adorno et al., 1950; Pettigrew, 2016), and political institutions (e.g. Solt, 2012; Stevens, Bishin, \& Barr, 2006), and so individuals and societies need to be prepared for COVID-19 to have multidimensional psychological and political consequences. 


\section{Methods \& Materials}

\section{Analytic Strategy}

We used a participant's zip code to aggregate the 241,249 individual authoritarian scores to the level of U.S. Combined Statistical Areas, U.S. States, and nations. Following previous geopsychological studies (e.g., Gebauer et al., 2017), we only kept spatial units with at least 100 observations. As is typical for online studies (Gosling, Vazire, Srivastava, \& John, 2004), our sample overrepresented female $(75.5 \%)$ and young $\left(M_{\text {Age }}=31.02, S D=10.29\right)$ participants. We therefore followed previous research (Ebert et al., 2019; Steutzer et al., 2018) and applied poststratification to account for this skewed sample composition. Specifically, we created six categories consisting of three age groups (18-24, 25-34 and older than 34) per both genders. We then calculated sampling weights by dividing the share per age-gender category in our sample by the share of people per age-gender category in the actual population. That way, a person that is underrepresented in our data (e.g., an old male) receives a weight that is greater than one, while a person that is overrepresented (e.g., a young female) receives a weight that is smaller than one.

\section{Pathogen Prevalence Measures}

In order to calculate regional infectious diseases or historical pathogen prevalence rates, we followed established measures developed by past research.

Infectious disease prevalence: USA metropolitan regions. Following the methodological recommendations of Hackman \& Hruschka (2013), we obtained the number of cases of chlamydia and gonorrhea for each US county from the Center for Disease Control (CDC). We aggregated this data to the metropolitan levels and calculated the cases of chlamydia and gonorrhea per 100,000 people for each year between 2002 
and 2010. To account for annual fluctuations, our final index consisted of the average rate across these 9 years.

Infectious disease prevalence: USA states. The Centers for Disease Control (CDC) provides more extensive information on infectious diseases at the state level than the county level, so for the state level we relied on an index compiled by Fincher \& Thornhill (2012) which quantified the pathogen prevalence of all infectious diseases tracked by the CDC. Each state has a numerical value equal to the average z-score of a populationadjusted disease incidence score for the years 1993 to 2007. As noted by Fincher and Thornhill (2013), the standardization of the state variables produces a metric that evaluates a state's relative position in terms of parasite stress. We also aggregated the CDC index used above to calculate pathogen prevalence for the US metropolitan regions in order to create a state-level measure. All analyses replicated the Fincher and Thornhill measure.

Infectious disease prevalence: Nations. Two measures were used to calculate pathogen prevalence at the national level. (1) Historical prevalence of disease-causing parasites (Murray \& Schaller, 2010). This index is a numerical estimate of the relative overall historical prevalence of disease in the country, based on nine different infectious diseases (leishmanias, trypanosomes, leprosy, schistosomes, filariae, tuberculosis, malaria, dengue, and typhus; Murray, Schaller \& Suedfeld, 2013). The data to develop this measure were obtained by Murray and Schaller (2010) from old medical atlases and historical information related to disease prevalence. (2) Nonzoonotic and zoonotic pathogen prevalence (Fincher \& Thornhill, 2012). Thornhill and Fincher (2012) used the Global Infectious Diseases \& Epidemiology Network (GIDEON) database to calculate 
the prevalence of human-specific and multi-host infectious (nonzoonotic) diseases and zoonotic diseases per country. National values for the nonzoonotic and zoonotic parasite prevalence variables were extracted from Thornhill and Fincher's (2012) openly available dataset.

\section{Regional Socio-economic Variables}

To control for potential confounding socio-economic variables, all US-based analyses controlled for the following five variables. (1) Religiosity, indexed by the proportion of people with a religious affiliation, regardless of religious denomination; (2) economic climate, reflected by the regional unemployment rate; (3) ethnic composition, measured by the proportion of white people residing in the region relative to other ethnic groups; (4) educational attainment (human capital), reflected by the proportion of individuals in the region that have at least attended college; (5) industrial composition, proportion of people working in manufacturing industries. Data were obtained from the 2010 US Religion Census (http://www.usreligioncensus.org/) to quantify religiosity and from the 2016 American Community Survey (https://www.census.gov/programs-surveys/acs/news/data-

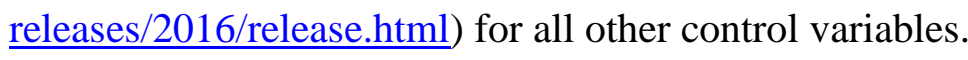

The cross-cultural analyses controlled for an analogous set of socio-economic variables, informed by covariates identified by past cross-cultural analyses of pathogen prevalence (Murray, Schaller, Suedfeld, 2013): (1) Economic climate was indexed by national unemployment rate as a percentage of the total labor force for 2016, obtained from the World Bank using the International Labour Organization estimate. (2) Religiosity was indexed by the proportion of people with a religious affiliation, regardless of religious denomination. (3) Life expectancy was measured using a method employed in previous cross-national studies (Fincher 
et al., 2008; Murray, Schaller, \& Suedfeld, 2013) in which average life expectancy at birth (obtained for the year 2013 from United Nations at www.hdr.undp.org) is regressed on historical pathogen prevalence index and the residuals are saved as the life expectancy index that is independent of disease-relevant threats. (4) Educational attainment (human capital) was indexed by the United Nations Education Index scores for the year 2013 (obtained from www.hdr.undp.org) and residualized in the same way as life expectancy. (5) Wealth inequality was indexed by GINI coefficients obtained from the CIA World Factbook (dates of GINI scores ranged from 1997-2016).

\section{Political Outcome Variables}

In order to calculate regional conservative voting behavior in the US, data were acquired from the MIT Election Data and Science Lab (2018). Conservative votes were operationalized as the number of votes for the Republican Presidential candidate (Donald Trump) divided by the total number of votes in a region. To calculate authoritarian governance across nations, we used the established Vanhanen democracy index from the latest year available, 2012 (Vanhanen, 1997; Pemstein, Meserve, \& Melton, 2013).

\section{Mediation Analysis}

Mediation analyses were conducted using the R packages psych (Revelle, 2015) for the biascorrected bootstrapping procedure and the R-based Monte Carlo Method for Assessing Mediation (MCMAM; Selig \& Preacher, 2008). The mediation effect size was calculated in accordance with the guidelines of Iacobucci, Saldanha, and Deng (2007) to compute the proportion of indirect effect to the total effect. 


\section{Bayesian Analysis}

Bayes factors express the relative likelihood of a regression model versus a null (or a specified alternative) model given the data and certain prior expectations. To calculate Bayes factors using Bayesian regression, we relied on a default Bayesian approach promoted by Wetzels and colleagues (2011), Rouder and Morey (2012), and Liang, Paulo, Molina, Clyde, and Berger (2008), and computationally specified in the R package BayesFactor (Morey et al., 2015).

\section{Data Acquisition}

The data were collected between June 2017 and October 2018 as part of a collaborative project between the authors and TIME Magazine (see Ebert, Götz, Obschonka, Zmigrod, \& Rentfrow, 2019; Götz, Bleidorn, \& Rentfrow, 2020), with the approval of the Psychology Research Ethics Committee of the institution (including a waiver of parental consent; application number: PRE.2017.044). The study was carried out as an online survey hosted, launched and advertised by TIME Magazine (http://time.com/4809884/harry-potter-house-sorting-hat-quiz) and included two parts, only available in English. The first part allowed people to complete established personality tests and receive feedback about their personality profile and how this would theoretically relate to the four fictional Hogwarts Houses from the Harry Potter saga. The second part - on which the present dataset is based - included an additional survey, which participants were notified was for additional scientific purposes and was independent of the first Harry Potter themed survey. This survey included the authoritarianism measure used here. Participants consented and opted-in to completing the second survey for research. They received no feedback on this second survey and so there was no incentive other than participation in research. All data and analysis scripts will be made available upon publication at the following link [insert link upon publication]. 


\section{Acknowledgements}

The authors would like to thank TIME Magazine, especially Chris Wilson for his generous support in developing, implementing, and distributing the survey used to collect the data.

\section{References}

Ackerman, J. M., Hill, S. E., \& Murray, D. R. (2018). The behavioral immune system: Current concerns and future directions. Social and Personality Psychology Compass, 12(2), e12371.

Bastian, B., Vauclair, C. M., Loughnan, S., Bain, P., Ashokkumar, A., Becker, M., ... \& Fischer, R. (2019). Explaining illness with evil: pathogen prevalence fosters moral vitalism. Proceedings of the Royal Society B, 286(1914), 20191576.

Beall, A. T., Hofer, M. K., \& Schaller, M. (2016). Infections and elections: Did an Ebola outbreak influence the 2014 US federal elections (and if so, how)? Psychological Science, 27(5), 595-605.

Brandt, M. J., \& Henry, P. J. (2012). Gender inequality and gender differences in authoritarianism. Personality and Social Psychology Bulletin, 38(10), 1301-1315.

Brandt, M. J., \& Reyna, C. (2014). To love or hate thy neighbor: The role of authoritarianism and traditionalism in explaining the link between fundamentalism and racial prejudice. Political Psychology, 35(2), 207-223.

Brown, M., Rodriguez, D. N., Gretak, A. P., \& Berry, M. A. (2017). Preliminary evidence for how the behavioral immune system predicts juror decision-making. Evolutionary Psychological Science, 3(4), 325-334.

Conway, L. G., Sexton, S. M., \& Tweed, R. G. (2006). Collectivism and governmentally initiated restrictions: A cross-sectional and longitudinal analysis across nations and within a nation. Journal of Cross-Cultural Psychology, 37(1), 20-41.

Conway, L. G., Bongard, K., Plaut, V., Gornick, L. J., Dodds, D. P., Giresi, T., ... \& Houck, S. C. (2017). Ecological origins of freedom: Pathogens, heat stress, and frontier topography predict more vertical but less horizontal governmental restriction. Personality and Social Psychology Bulletin, 43(10), 1378-1398.

Conway, L. G., Houck, S. C., Gornick, L. J. (2014). Regional differences in individualism and why they matter. In Rentfrow, J. (Ed.), Psychological geography (pp. 3150). Washington, DC: American Psychological Association.

Crawford, J. T., Brandt, M. J., Inbar, Y., \& Mallinas, S. R. (2016). Right-wing authoritarianism predicts prejudice equally toward "gay men and lesbians" and "homosexuals". Journal of Personality and Social Psychology, 111(2), e31.

Ebert, T., Götz, F. M., Obschonka, M., Zmigrod, L., \& Rentfrow, P. J. (2019). Regional variation in courage and entrepreneurship: The contrasting role of courage for the emergence and survival of start-ups in the United States. Journal of Personality, 87, 1039-1055. doi:10.1111/jopy.12454

Faulkner, J., Schaller, M., Park, J. H., \& Duncan, L. A. (2004). Evolved diseaseavoidance mechanisms and contemporary xenophobic attitudes. Group Processes \& Intergroup Relations, 7(4), 333-353. 
Federico, C. M., Fisher, E. L., \& Deason, G. (2011). Expertise and the ideological consequences of the authoritarian predisposition. Public opinion quarterly, 75(4), 686-708.

Feldman, S., \& Stenner, K. (1997). Perceived threat and authoritarianism. Political Psychology, 18(4), 741-770.

Fincher, C. L., \& Thornhill, R. (2012). Parasite-stress promotes in-group assortative sociality: The cases of strong family ties and heightened religiosity. Behavioral and Brain Sciences, 35(2), 61-79.

Fincher, C. L., Thornhill, R., Murray, D. R., \& Schaller, M. (2008). Pathogen prevalence predicts human cross-cultural variability in individualism/collectivism. Proceedings of the Royal Society B: Biological Sciences, 275(1640), 1279-1285.

Garretsen, H., Stoker, J. I., Soudis, D., Martin, R. L., \& Rentfrow, P. J. (2018). Brexit and the relevance of regional personality traits: more psychological Openness could have swung the regional vote. Cambridge Journal of Regions, Economy and Society, 11(1), 165175.

Gebauer, J. E., Sedikides, C., Schönbrodt, F. D., Bleidorn, W., Rentfrow, P. J., Potter, J., \& Gosling, S. D. (2017). The religiosity as social value hypothesis: A multi-method replication and extension across 65 countries and three levels of spatial aggregation. Journal of Personality and Social Psychology, 113, 18-39.

Gosling, S. D., Vazire, S., Srivastava, S., \& John, O. P. (2004). Should we trust webbased studies? A comparative analysis of six preconceptions about internet questionnaires. American psychologist, 59(2), 93.

Götz, F. M., Bleidorn, W., \& Rentfrow, P. J. (2020). Age differences in Machiavellianism across the life span: Evidence from a large-scale cross-sectional study. Journal of Personality. doi:10.1111/jopy.12545

Hackman, J., \& Hruschka, D. (2013). Fast life histories, not pathogens, account for state-level variation in homicide, child maltreatment, and family ties in the US. Evolution and Human Behavior, 34(2), 118-124.

Hayes, A. F., \& Scharkow, M. (2013). The relative trustworthiness of inferential tests of the indirect effect in statistical mediation analysis: Does method really matter?. Psychological science, 24(10), 1918-1927.

Helzer, E. G., \& Pizarro, D. A. (2011). Dirty liberals! Reminders of physical cleanliness influence moral and political attitudes. Psychological science, 22(4), 517-522.

Hetherington, M., \& Suhay, E. (2011). Authoritarianism, threat, and Americans' support for the war on terror. American Journal of Political Science, 55(3), 546-560.

Hetherington, M. J., \& Weiler, J. D. (2009). Authoritarianism and polarization in American politics. Cambridge University Press.

Horita, Y., \& Takezawa, M. (2018). Cultural differences in strength of conformity explained through pathogen stress: A statistical test using hierarchical Bayesian estimation. Frontiers in psychology, 9, 1921.

Inbar, Y., Pizarro, D. A., \& Bloom, P. (2009). Conservatives are more easily disgusted than liberals. Cognition and emotion, 23(4), 714-725.

Jones, A., \& Fitness, J. (2008). Moral hypervigilance: the influence of disgust sensitivity in the moral domain. Emotion, 8(5), 613. 
Kavaliers, M., \& Choleris, E. (2018). The role of social cognition in parasite and pathogen avoidance. Philosophical Transactions of the Royal Society B: Biological Sciences, 373(1751), 20170206.

Iacobucci, D., Saldanha, N., \& Deng, X. (2007). A meditation on mediation: Evidence that structural equations models perform better than regressions. Journal of consumer psychology, 17(2), 139-153.

Kim, H. S., Sherman, D. K., \& Updegraff, J. A. (2016). Fear of Ebola: The influence of collectivism on xenophobic threat responses. Psychological Science, 27(7), 935-944.

Letendre, K., Fincher, C. L., \& Thornhill, R. (2010). Does infectious disease cause global variation in the frequency of intrastate armed conflict and civil war?. Biological Reviews, 85(3), 669-683.

Liang, F., Paulo, R., Molina, G., Clyde, M. A., \& Berger, J. O. (2008). Mixtures of g priors for Bayesian variable selection. Journal of the American Statistical Association, 103(481), 410-423.

Liuzza, M. T., Olofsson, J. K., Cancino-Montecinos, S., \& Lindholm, T. (2019). Body Odor Disgust sensitivity predicts stronger moral harshness towards moral violations of purity. Frontiers in psychology, 10, 458.

Liuzza, M. T., Lindholm, T., Hawley, C. B., Gustafsson Sendén, M., Ekström, I., Olsson, M. J., \& Olofsson, J. K. (2018). Body odour disgust sensitivity predicts authoritarian attitudes. Royal Society open science, 5(2), 171091.

MacKinnon, D. P., \& Fairchild, A. J. (2009). Current directions in mediation analysis. Current directions in psychological science, 18(1), 16-20.

Mavor, K. I., Macleod, C. J., Boal, M. J., \& Louis, W. R. (2009). Right-wing authoritarianism, fundamentalism and prejudice revisited: Removing suppression and statistical artefact. Personality and Individual Differences, 46(5-6), 592-597.

Mavor, K. I., Louis, W. R., \& Laythe, B. (2011). Religion, prejudice, and authoritarianism: Is RWA a boon or bane to the psychology of religion?. Journal for the scientific study of religion, 50(1), 22-43.

MIT Election Data and Science Lab, 2018, "County Presidential Election Returns 20002016", https://doi.org/10.7910/DVN/VOQCHQ, Harvard Dataverse, V6, UNF:6:ZZe1 xuZ5H214NUiSRcRf8Q== [fileUNF]

Morey, R. D., Rouder, J. N., Jamil, T., \& Morey, M. R. D. (2015). Package 'bayesfactor'. URLh http://cran/r-projectorg/web/packages/BayesFactor/BayesFactor pdf $i$ (accessed 1006 15).

Murray, D. R., \& Schaller, M. (2010). Historical prevalence of infectious diseases within 230 geopolitical regions: A tool for investigating origins of culture. Journal of CrossCultural Psychology, 41(1), 99-108.

Murray, D. R., \& Schaller, M. (2016). The behavioral immune system: Implications for social cognition, social interaction, and social influence. In Advances in experimental social psychology (Vol. 53, pp. 75-129). Academic Press.

Murray, D. R., Schaller, M., \& Suedfeld, P. (2013). Pathogens and politics: Further evidence that parasite prevalence predicts authoritarianism. PloS One, 8(5). 
Murray, D. R., Trudeau, R., \& Schaller, M. (2011). On the origins of cultural differences in conformity: Four tests of the pathogen prevalence hypothesis. Personality and Social Psychology Bulletin, 37(3), 318-329.

Murray, D. R., Kerry, N., \& Gervais, W. M. (2019). On disease and deontology: multiple tests of the influence of disease threat on moral vigilance. Social Psychological and Personality Science, 10(1), 44-52.

Navarrete, C. D., \& Fessler, D. M. (2006). Disease avoidance and ethnocentrism: The effects of disease vulnerability and disgust sensitivity on intergroup attitudes. Evolution and Human Behavior, 27(4), 270-282.

Obschonka, M., Stuetzer, M., Rentfrow, P. J., Lee, N., Potter, J., \& Gosling, S. D. (2018). Fear, populism, and the geopolitical landscape: the "sleeper effect" of neurotic personality traits on regional voting behavior in the 2016 Brexit and Trump elections. Social Psychological and Personality Science, 9(3), 285-298.

Pemstein, D., Meserve, S. A., \& Melton, J. (2013). Replication data for: Democratic Compromise: A Latent Variable Analysis of Ten Measures of Regime Type. https://doi.org/10.7910/DVN/WWYOHU, Harvard Dataverse, V2

Pettigrew, T. F. (2016). In pursuit of three theories: Authoritarianism, relative deprivation, and intergroup contact. Annual review of psychology, 67, 1-21.

Preacher, K. J., \& Selig, J. P. (2012). Advantages of Monte Carlo confidence intervals for indirect effects. Communication Methods and Measures, 6(2), 77-98.

Rentfrow, P. J. (2010). Statewide differences in personality: toward a psychological geography of the United States. American Psychologist, 65(6), 548.

Rentfrow, P. J., Gosling, S. D., Jokela, M., Stillwell, D. J., Kosinski, M., \& Potter, J. (2013). Divided we stand: Three psychological regions of the United States and their political, economic, social, and health correlates. Journal of personality and social psychology, 105(6), 996.

Revelle, W.(2015). Package 'psych'. The Comprehensive R Archive Network.

Schaller, M., Murray, D. R., \& Bangerter, A. (2015). Implications of the behavioural immune system for social behaviour and human health in the modern world. Philosophical Transactions of the Royal Society B: Biological Sciences, 370(1669), 20140105.

Schnall, S. (2017). Disgust as embodied loss aversion. European Review of Social Psychology, 28(1), 50-94.

Selig, J. P., \& Preacher, K. J. (2008, June). Monte Carlo method for assessing mediation: An interactive tool for creating confidence intervals for indirect effects [Computer software]. Available from http://quantpsy.org/.

Sevi, B., \& Eskenazi, T. (2018). The Impact of Perceived Threat of Infectious Disease on the Framing Effect. Evolutionary Psychological Science, 4(3), 340-346.

Stenner, K. (2005). The authoritarian dynamic. Cambridge University Press.

Stuetzer, M., Audretsch, D. B., Obschonka, M., Gosling, S. D., Rentfrow, P. J., \& Potter, J. (2018). Entrepreneurship culture, knowledge spillovers and the growth of regions. Regional Studies, 52, 608-618. 
Stevens, D., Bishin, B. G., \& Barr, R. R. (2006). Authoritarian attitudes, democracy, and policy preferences among Latin American elites. American Journal of Political Science, 50(3), 606-620.

Stewart, P. A., Adams Jr, T. G., \& Senior, C. (2020). The Effect of Trait and State Disgust on Fear of God and Sin. Frontiers in Psychology, 11.

Solt, F. (2012). The social origins of authoritarianism. Political Research Quarterly, 65(4), 703-713.

Terrizzi, J. A., Shook, N. J., \& McDaniel, M. A. (2013). The behavioral immune system and social conservatism: A meta-analysis. Evolution and Human Behavior, 34(2), 99-108.

Thornhill, R., Fincher, C. L., \& Aran, D. (2009). Parasites, democratization, and the liberalization of values across contemporary countries. Biological Reviews, 84(1), 113-131.

Thornhill, R., Fincher, C. L., Murray, D. R., \& Schaller, M. (2010). Zoonotic and nonzoonotic diseases in relation to human personality and societal values: Support for the parasitestress model. Evolutionary Psychology, 8(2), 147470491000800201.

Tybur, J. M., Inbar, Y., Aarøe, L., Barclay, P., Barlow, F. K., De Barra, M., ... \& Consedine, N. S. (2016). Parasite stress and pathogen avoidance relate to distinct dimensions of political ideology across 30 nations. Proceedings of the National Academy of Sciences, 113(44), 12408-12413.

Van Leeuwen, F., Park, J. H., Koenig, B. L., \& Graham, J. (2012). Regional variation in pathogen prevalence predicts endorsement of group-focused moral concerns. Evolution and Human Behavior, 33(5), 429-437.

van Leeuwen, F., \& Petersen, M. B. (2018). The behavioral immune system is designed to avoid infected individuals, not outgroups. Evolution and Human Behavior, 39(2), 226-234.

Vanhanen, T. (1997). Prospects of democracy: A study of 172 countries. Psychology Press.

Wetzels, R., Matzke, D., Lee, M. D., Rouder, J. N., Iverson, G. J., \& Wagenmakers, E. J. (2011). Statistical evidence in experimental psychology: An empirical comparison using 855 t tests. Perspectives on Psychological Science, 6(3), 291-298.

Wu, B. P., \& Chang, L. (2012). The social impact of pathogen threat: How disease salience influences conformity. Personality and Individual Differences, 53(1), 50-54.

Zakrzewska, M., Olofsson, J. K., Lindholm, T., Blomkvist, A., \& Liuzza, M. T. (2019). Body odor disgust sensitivity is associated with prejudice towards a fictive group of immigrants. Physiology \& behavior, 201, 221-227.

Zmigrod, L., Rentfrow, P. J., \& Robbins, T. W. (2018). Cognitive underpinnings of nationalistic ideology in the context of Brexit. Proceedings of the National Academy of Sciences, 115(19), E4532-E4540.

Zmigrod, L., Rentfrow, P. J., \& Robbins, T. W. (2019a). The partisan mind: Is extreme political partisanship related to cognitive inflexibility?. Journal of Experimental Psychology: General.

Zmigrod, L., Rentfrow, P. J., \& Robbins, T. W. (2019b). Cognitive inflexibility predicts extremist attitudes. Frontiers in psychology, 10, 989.

Zmigrod, L. (2020). The role of cognitive rigidity in political ideologies: theory, evidence, and future directions. Current Opinion in Behavioral Sciences, 34, 34-39. 